\title{
SHIP1 inhibits cell growth, migration, and invasion in non-small cell lung cancer through the PI3K/AKT pathway
}

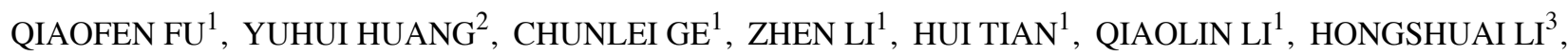 \\ RUILEI LI ${ }^{1}$, XINGYU TAO ${ }^{1,4}$, YUANBO XUE ${ }^{1}$, YING WANG ${ }^{1}$, GUANQIN YANG $^{5}$, \\ WEIYI FANG ${ }^{6}$ and XIN SONG ${ }^{1}$ \\ ${ }^{1}$ Department of Cancer Biotherapy Center, Third Affiliated Hospital of Kunming Medical University \\ (Tumor Hospital of Yunnan Province), Kunming, Yunnan 650118; \\ ${ }^{2}$ Yunnan Tin Group Company Limited Institute of Labor Protection, Gejiu, Yunnan 661400; \\ ${ }^{3}$ Department of Abdominal Oncology, Cancer Center, West China Hospital, Sichuan University, Chengdu, \\ Sichuan 610041; ${ }^{4}$ Cancer Research Institute of Southern Medical University, Guangzhou, Guangdong 510515; \\ ${ }^{5}$ Medical Department of Yunnan Cancer Hospital, Kunming, Yunnan 650118; ${ }^{6}$ Cancer Center, \\ Traditional Chinese Medicine-Integrated Hospital of Southern Medical University, \\ Guangzhou, Guangdong 510310, P.R. China
}

Received August 23, 2018; Accepted January 25, 2019

DOI: $10.3892 /$ or.2019.6990

\begin{abstract}
Src homology 2-containing inositol-5'-phosphatase 1 (SHIP1) serves a vital role in the occurrence and development of hematological tumors, but there is limited knowledge regarding the role of SHIP1 in various solid tumors, including lung cancer. In the present study, the aim was to investigate the expression and functional mechanisms of SHIP1 in non-small cell lung cancer (NSCLC). The Gene Expression Omnibus database demonstrated that SHIP1 had low expression in NSCLC. Further studies using fresh tissues and cell lines also confirmed this observation. Biological function analyses revealed that SHIP1 overexpression notably suppressed cell growth, migration and invasion in vitro and in vivo in NSCLC. Mechanistic analyses indicated that SHIP1 inactivated the phosphoinositide 3-kinase (PI3K)/AKT pathway to suppress signals associated with the cell cycle and epithelial-mesenchymal transition. In clinical specimens,
\end{abstract}

Correspondence to: Professor Weiyi Fang, Cancer Center, Traditional Chinese Medicine-Integrated Hospital of Southern Medical University, 13 ShiLiuGang Road, Guangzhou, Guangdong 510310, P.R. China

E-mail: fangweiyi1975@163.com

Professor Xin Song, Department of Cancer Biotherapy Center, Third Affiliated Hospital of Kunming Medical University (Tumor Hospital of Yunnan Province), 519 Kunzhou Road, Kunming, Yunnan 650118, P.R. China

E-mail: songxin68@126.com

Key words: Src homology 2-containing inositol-5'-phosphatase 1, non-small cell lung cancer, phosphoinositide 3-kinase/AKT, epithelial-mesenchymal transition reduced SHIP1 is an unfavorable factor and is negatively associated with the $\mathrm{T}$ classification, $\mathrm{N}$ classification and clinical stage. Furthermore, patients with low SHIP1 levels exhibited reduced survival rate, compared with patients with high levels of the protein. Notably, the promoter of the SHIP1 gene lacks $\mathrm{CpG}$ islands, and the suppression of SHIP1 expression is not associated with epidermal growth factor receptor or Kirsten rat sarcoma mutations. Thus, the present study demonstrated that SHIP1 inhibits cell growth, migration and invasion in NSCLC through the PI3K/AKT pathway. Additionally, reduced SHIP1 expression may be an unfavorable factor for NSCLC.

\section{Introduction}

The phospholipid bilayer is the basic scaffold of cell membranes, and inositol phospholipids serve an important role in cell transmembrane signal transduction in eukaryotes (1). The abnormal expression or dysfunction of inositol kinases and phosphatases are implicated in a number of human diseases, including preeclampsia, inflammation and cancer (1-4). As an inositol phosphatase, Src homology 2 domain-containing inositol 5'-phosphatase (SHIP) is encoded by the inositol polyphosphate-5-phosphatase D gene and was identified in $1996(5,6)$. SHIP1 is primarily expressed in the hematopoietic system (7), where it functions as a key regulator of immunoreceptor signaling (8), a negative controller of hematopoietic progenitor cell proliferation (9) and an inducer of cellular apoptosis (10). In recent years, the abnormal expression or activity of SHIP1 has been demonstrated to be involved in a variety of diseases, including Alzheimer's disease (11), Crohn's disease (12), diabetic kidney disease (13) and hematological tumors (14).

As a hematopoietic-restricted phosphatidylinositol phosphatase, SHIP1 serves a vital role in driving the occurrence and development of hematological tumors $(10,14)$. 
SHIP1 downregulates PI3K-mediated signaling and suppresses cell proliferation, differentiation, survival and migration of hematopoietic cells (15). PI3K is a central signal component for this major cell signaling pathway and influences various cellular functions, including cell proliferation, metastasis and apoptosis (16). Furthermore, phosphatidylinositol-3,4,5-trisphosphate $[\mathrm{PI}(3,4,5) \mathrm{P} 3]$ is a key PI3K-generated secondary messenger that is required for PI3K pathway activity (17). Once activated by extracellular stimuli, PI3K can quickly synthesize $\mathrm{PI}(3,4,5) \mathrm{P} 3, \mathrm{PI}(3,4,5)$ $\mathrm{P} 3$ is located on the plasma membrane and directly binds and thereby recruits signaling proteins, including protein kinase B (AKT) and phosphoinositide-dependent kinase 1 (PDK1) $(16,18)$. The activation of these proteins initiates more signaling cascades to induce various cellular functions, including cell proliferation, migration and cell cycle transition (19). SHIP antagonizes PI3K activity by dephosphorylating the key PI3K-generated secondary messenger $\mathrm{PI}(3,4,5) \mathrm{P} 3$, resulting in the suppression of cell proliferation, migration and cell cycle progression in hematological tumors (15). Notably, recent research on SHIP1 is primarily focused on hematological tumors $(7,9,10,14,15)$, and there is limited knowledge regarding the role of SHIP1 in various solid tumors, including lung cancer.

Lung cancer is one of the most common carcinomas globally and is characterized by hidden onset, high malignancy and potent invasion $(20,21)$. Lung cancer represents the leading cause of cancer-associated mortalities worldwide, according to the epidemiological report published in 2018 (20). As the most common type of lung cancer, non-small cell lung cancer (NSCLC) accounts for $\sim 85 \%$ of all lung cancer types (21). Emerging evidence indicates that NSCLC formation and progression is a multistage process involving the activation of proto-oncogenes and the inactivation of tumor suppressor genes $(21,22)$. Thus, gene therapy and small molecule inhibitors targeting epidermal growth factor receptor (EGFR) have become the most prevalent approach for the treatment of NSCLC (22). However, although EGFR-targeted therapy offers new hope to patients with NSCLC, drug resistance has become increasingly prominent (22). Recent studies have identified a number of mechanisms of resistance to EGFR-tyrosine kinase inhibitors (EGFR-TKIs), including secondary EGFR mutations, the activation of alternative signaling pathways (Met and hepatocyte growth factor), the aberrant activation of downstream pathways, including AKT mutations, and the loss of suppressors, such as phosphatase and tensin homology (PTEN) (21-25). PTEN and SHIP negatively regulate the EGFR-mediated PI3K pathway $(24,25)$, but the expression pattern and functional mechanisms of SHIP1 in NSCLC have not been investigated.

In the present study, it was demonstrated that SHIP1 expression is reduced in NSCLC and is associated with tumor progression. However, no notable association with EGFR and Kirsten rat sarcoma (KRAS) mutations was observed. Furthermore, in the present study, it was determined that SHIP1 overexpression suppresses cell proliferation, migration, invasion and tumorigenicity via the PI3K/AKT pathway. These data provide novel insights into the molecular function of SHIP1 in NSCLC and solid tumors.

\section{Materials and methods}

Cell culture and sample collection. The A549 and H1975 cell lines were obtained from the American Type Culture Collection (Manassas, VA, USA), and the SPCA-1 and 16HBE cell lines were purchased from the Chinese Academy of Sciences Cell Bank (Shanghai, China). These cells were confirmed to be free of mycoplasma with a Polymerase Chain Reaction (PCR) kit (cat. no. Myco-P-50; Shanghai Inflammation XI Biological Technology Co., Ltd., Shanghai, China) (http://biothrive2016. cnbio.net/) (26). A549 cells were cultured in Dulbecco's modified Eagle's medium (DMEM; Gibco; Thermo Fisher Scientific, Inc., Waltham, MA, USA) supplemented with $10 \%$ fetal bovine serum (FBS; Shanghai ExCell Biology, Inc., Shanghai, China). SPCA-1 and H1975 cells were cultured in RPMI-1640 medium (Gibco; Thermo Fisher Scientific, Inc.) supplemented with $10 \%$ FBS. Additionally, 16HBE cells, an immortalized human bronchial epithelial cell line, were grown in DMEM supplemented with 20\% FBS. All cells were incubated in a humidified chamber with $5 \% \mathrm{CO}_{2}$ at $37^{\circ} \mathrm{C}$.

To examine the expression of SHIP1 mRNA in NSCLC tissues, a total of 26 surgically-resected fresh primary lung adenocarcinoma tissues and paired normal lung tissues were obtained from the Third Affiliated Hospital of Kunming Medical University (Kunming, China). Clinical protocols were approved by the Ethics Committees of the Third Affiliated Hospital of Kunming Medical University, and patients provided informed consent. The tissue array included 146 NSCLC tissues (68 paraffin-embedded primary adenocarcinoma specimens and 78 squamous carcinoma specimens) and 59 normal specimens, was obtained from Shanghai Outdo Biotech Co., Ltd. (Shanghai, China). Patients with a diagnosed relapse, as well as those who received preoperative radiation, chemotherapy or biotherapy were excluded. Demographic and clinical data were obtained from the patients' medical records.

$R N A$ isolation, reverse transcription-PCR (RT-PCR), $R T$-quantitative PCR (RT-qPCR), and primers. Analysis of relative gene expression data was conducted using RT-qPCR and the $2^{-\triangle \Delta C q}$ method (27). Total RNA isolation, RT-PCR and RT-qPCR were performed as described in our previous study (28). SHIP1-specific primers sequences were as follows: Sense, 5'-TTTACGTGATCGGCACCCAA-3'; and antisense, 5'-GTGGCTGTTGACGAACCCTA-3'. ADP ribosylation factor 5 was used as an internal control based on the following primers: Sense, 5'-ATCTGTTTCACAGTCTGGGAC G-3'; and antisense, 5'-CCTGCTTGTTGGCAAATACC-3'. Experiments were performed according to the instructions of a RT-qPCR kit (RR064A; Takara Bio, Inc., Otsu, Japan). The RT-qPCR reactions for each sample were repeated thrice. Independent experiments were performed in triplicate.

Western blot analysis, reagent and antibodies. Western blot analysis was performed as previously described (28), using: Anti-SHIP1 (cat. no. 19694-1-AP), $\alpha$-tubulin (cat. no. 11224-1-AP; internal control) and KRAS (cat. no. 12063-1-AP) antibodies (1:1,000; ProteinTech Group, Inc., Chicago, IL, USA); anti-cyclin D1 (cat. no. ab134175), cyclin dependent kinase 4 (CDK4; cat. no. ab108357), CDK6 (cat.no. ab124821),EGFR (cat.no. ab52894), phospho(p)-EGFR 
(cat. no. ab40815), AKT (cat. no. ab8805) and p-AKT (Ser473; cat. no. ab18206) antibodies (1:1,000; Abcam, Cambridge, MA, USA); and anti-Vimentin (cat. no. 5741), $\beta$-catenin (cat. no. 8480), N-cadherin (cat. no. 13116) and E-cadherin (cat. no. 3195) antibodies (1:1,000; Cell Signaling Technology, Inc., Danvers, MA, USA). Horseradish peroxidase-conjugated anti-rabbit/mouse IgG antibodies were used as the secondary antibodies (1:8,000; Cell Signaling Technology, Inc.). Signals were detected using enhanced chemiluminescence reagents (EMD Millipore, Billerica, MA, USA). Recombinant human EGF (cat. no. PHG0311) was purchased from Gibco (Thermo Fisher Scientific, Inc.) and dissolved in PBS and stored at $-20^{\circ} \mathrm{C}$. The usage concentration of EGF was $100 \mathrm{ng} / \mathrm{ml}$. LY294002, an inhibitor of the PI3K/AKT pathway, which was used to inactivate the PI3K/AKT signals in the present study, was purchased from Beyotime Institute of Biotechnology (Haimen, China).

Inhibition of the PI3K/AKT pathway. To analysis the effect of PI3K/AKT pathway on cell proliferation and metastasis, LY294002 was added to DMEM at a final concentration of $20 \mu \mathrm{M}$. Untreated A549 cells were taken as the control group and the treated cells as the suppression group. After culturing for $48 \mathrm{~h}$ in a humidified chamber with $5 \% \mathrm{CO}_{2}$ at $37^{\circ} \mathrm{C}$, the cell cycle- and EMT-associated factors were analyzed by western blot analysis, according to the aforementioned protocol.

Lentivirus and plasmid production, infection and transient transfection. SHIP1 plasmid or control vectors containing green fluorescence protein that could be packaged for recombinant lentivirus were purchased from TranSheepBio (Shanghai, China). Lentiviral particles carrying full-length hsa-SHIP1 vector and their flanking control (NC) were constructed. Subsequently, A549 and SPCA-1 cells were infected with lentiviral vector as described in our previous study (28). The transient transfection of plasmid was performed as described previously (26).

MTT assay. Cell proliferation was assessed using MTT as previously described (29). The cells were seeded at a density of $3 \times 10^{3}$ cells/well for 4 days. For each experimental condition, five parallel wells were assigned to each group. Experiments were performed in triplicate.

Cell cycle analysis. Cell cycle examination was performed as previously described (30). NSCLC cells were cultured for $24 \mathrm{~h}$ with serum-free DMEM. Subsequently, the SHIP1 and control plasmids were separately transfected into NSCLC cells for $48 \mathrm{~h}$, and the DNA content of labeled cells was measured using a BD FACSCanto ${ }^{\mathrm{TM}}$ II Flow Cytometer (BD Biosciences; Beckon, Dickinson and Company, Franklin Lakes, NJ, USA) and analyzed with ModFit LT software version 3.2 (Verity Software House, Inc., Topsham, ME, USA).

Cell migration and invasion assays. In vitro cell migration and invasion assays were examined according to our previous study (28). For Transwell assays, $1 \times 10^{5}$ cells in a $100 \mu 1$ DMEM without serum were seeded on a fibronectin-coated polycarbonate membrane insert in a Transwell apparatus (Corning, Inc., Corning, NY, USA). In the lower surface,
$500 \mu 1$ DMEM with $10 \%$ FBS was added as chemoattractant. After the cells were incubated for $10 \mathrm{~h}$ at $37^{\circ} \mathrm{C}$ in a $5 \% \mathrm{CO}_{2}$ atmosphere, Giemsa stained cells adhering to the lower surface were counted under an optical microscope (DMI 4000B; Leica $\mathrm{GmbH}$, Wetzlar, Germany) in five predetermined fields (x100 magnification). All assays were independently repeated at least thrice. For Boyden assays, the procedure was similar to the cell migration assay, except that the Transwell membranes were pre-coated with $24 \mu \mathrm{g} / \mathrm{ml}$ Matrigel (R\&D Systems, Inc., Minneapolis, MN, USA).

In vivo tumorigenesis and metastasis assays. In vivo tumorigenesis in nude mice was performed based on our previous study (28), and a total of 24 mice were purchased from Experimental Animal Center of Kunming Medical University. Mice were maintained in a barrier facility on high efficiency particulate air-filtered racks, which is a specific pathogen-free animal facility with a light/dark cycle of $12 / 12 \mathrm{~h}$, temperature of $22 \pm 2^{\circ} \mathrm{C}$, humidity of $50 \pm 10 \%$, and had unlimited access to irradiated food and sterilized water. D-Hank's solution was prepared with sodium chloride $(8 \mathrm{~g})$, potassium chloride $(0.4 \mathrm{~g})$, potassium dihydrogen phosphate $(0.06 \mathrm{~g})$, sodium bicarbonate $(0.35 \mathrm{~g})$ and disodium hydrogen phosphate dodecahydrate $(0.15 \mathrm{~g})$ in $1,000 \mathrm{ml}$ distilled water. Subsequently, a total of $5 \times 10^{6}$ logarithmically-growing stable SHIP1-overexpressing or control A549 cells in $0.1 \mathrm{ml}$ D-Hank's solution were subcutaneously inoculated into the left-right symmetric flank of 4- to 6-week-old female BALB/c-nu/nu mice (n=6/group). Tumor volumes were measured every 3 days. When the largest tumor diameter reached $1.5 \mathrm{~cm}$ or progressive tumor growth was evident, the mice were sacrificed by cervical dislocation and tumors were excised and weighed. All animal studies were approved by the Animal Research and Care Committee of Kunming Medical University (Kunming, China).

In vivo metastasis assays were performed according to our previous study (31). A total of $5 \times 10^{6}$ stable SHIP1-overexpressing or control A549 cells were injected under the liver capsule of 4- to 6-week-old female BALB/c-nu/nu mice ( $n=6$ for SHIP1-overexpressing group or control group). The optical fluorescence images $(x 1)$ were visualized to monitor primary tumor growth and formation of metastatic lesions by Living Image Software (version 2.50; PerkinElmer, Inc., Waltham, MA, USA). After 40 days, all mice were sacrificed by cervical dislocation. Livers were removed, and metastatic tissues were analyzed by hematoxylin and eosin staining according to our previous study (28).

Immunohistochemistry. Immunohistochemistry was performed based on our previous study (28). The tissues were fixed in $10 \%$ formalin within $48 \mathrm{~h}$ at room temperature and embedded in paraffin. Paraffin sections $(4 \mu \mathrm{m})$ from samples were deparaffinized in $100 \%$ xylene and rehydrated in descending ethanol series (100, 100, 95, 85, 80 and 75\%) and water. Heat-induced antigen retrieval was performed in $10 \mathrm{mM}$ citrate buffer (cat. no. MVS-0100; Fuzhou Maixin Biotech Co., Ltd., Fuzhou, China) for $2 \mathrm{~min}$ at $100^{\circ} \mathrm{C}$. Endogenous peroxidase activity and non-specific antigens were blocked with peroxidase blocking reagent containing $3 \%$ hydrogen peroxide and goat serum (cat. no. SP KIT-B3; Fuzhou Maixin Biotech Co., Ltd.), followed by incubation with 
a SHIP1 antibody (1:500; ProteinTech Group, Inc.) overnight at $4^{\circ} \mathrm{C}$. After washing 3 times, sections were incubated with undiluted rabbit secondary antibodies from a Dako REAL EnVision detection system/Horseradish Peroxidase for rabbit/mouse secondary antibodies kit (cat. no. k5007; DAKO; Agilent Technologies, Inc., Santa Clara, CA, USA) for $30 \mathrm{~min}$ followed by streptavidin-conjugated horseradish peroxidase for $30 \mathrm{~min}$ at $37^{\circ} \mathrm{C}$. The peroxidase reaction was developed using 3,3-diaminobenzidine (DAB) chromogen solution with DAKO. Sections were visualized with DAB, counterstained with hematoxylin for $2 \mathrm{~min}$ at room temperature, mounted in neutral gum and analyzed using an optical microscope (DMI 4000B; Leica GmbH).

Evaluation of staining. Stained tissue sections were reviewed and scored independently by two investigators blinded to the clinical data. The score was based on the sum of staining intensity and the percentage of stained cells. The staining intensity was scored as previously described (0-3) (28), and the percentage of positive staining areas of cells was defined as a scale of $0-3(0,<10 \% ; 1,10-25 \% ; 2,26-75 \%$; and $3,>76 \%)$. The sum of the staining intensity and staining extent scores (0-6) was used as the final staining score. For statistical analysis, a final staining score of 0-2 and 3-6 were considered to be negative and positive expression levels, respectively.

Use of database. To assess the expression of SHIP1 in NSCLC, Affymetrix HG-U133_Plus_2 array data were extracted from Gene Expression Omnibus (GEO) (https://www.ncbi.nlm.nih. gov/gds/?term). The GSE19188 dataset (32) was included in the present study and the genome-wide gene expression analysis from 91 NSCLC and 65 normal lung tissue samples were extracted. To analyze the association between SHIP1 expression and EGFR/KRAS mutations in NSCLC, the GSE75037 dataset (33) which used Illumina WG6-V3 expression arrays to profile the gene expression signature in 83 lung adenocarcinomas and 83 matched adjacent non-malignant lung tissues, was included in the present study. To investigate the prognostic effect of SHIP1 on patients with NSCLC, the Kaplan-Meier Plotter database (http://kmplot.com/analysis/index. php?cancer=lung\&p=service) was use to predict the overall survival rates. To analyze whether low SHIP1 expression results from SHIP1 promoter methylation, the EMBOSS Cpgplot (http://www.ebi.ac.uk/Tools/seqstats/emboss_cpgplot/) was use to predict the $\mathrm{CpG}$ islands in the SHIP1 promoter.

Statistical analysis. All data were independently repeated in triplicate. SPSS 13.0 (SPSS, Inc., Chicago, IL, USA) and Graph Pad Prism 5.0 software (GraphPad Software, Inc., La Jolla, CA, USA) were used for statistical analysis. Data are expressed as the mean \pm standard deviation from at least 3 independent experiments. Student's t-test was employed for analysis between two groups, one-way analysis of variance with post hoc contrasts by Dunnett's test was employed for analysis between 3 groups, and a parametric generalized linear model with random effects was employed for analysis of tumor growth and MTT assay results. Analysis of SHIP1 expression in 26 fresh primary NSCLC tissues and 83 lung adenocarcinoma tissues (GSE75037) were performed using a paired-samples Student's t-test. The $\chi^{2}$ test was used to determine the differences in SHIP1 protein expression between NSCLC tissues and non-cancerous lung tissues. Survival analysis was performed using the Kaplan-Meier method with the log-rank test. A multivariate Cox proportional hazards method was used to analyze the association between the variables and patient's survival time. $\mathrm{P}<0.05$ was considered to indicate a statistically significant difference.

\section{Results}

SHIP1 is downregulated in NSCLC. To assess the expression of SHIP1 in NSCLC, Affymetrix HG-U133_Plus_2 array data were extracted from the GEO GSE19188 dataset. The genome-wide gene expression analysis from 91 NSCLC and 65 that normal lung tissue samples was included in the GSE19188 dataset. SHIP1 expression was analyzed in these samples and it was determined that SHIP1 expression was significantly reduced in NSCLC samples, compared with normal lung tissues (Fig. 1A). Furthermore, RT-qPCR was used to detect SHIP1 mRNA levels in 26 fresh primary NSCLC and paired adjacent normal lung tissues. Consistently, mean SHIP1 mRNA levels were significantly reduced in NSCLC tissues, compared with the paired adjacent normal lung tissues (Fig. 1B). A panel of human NSCLC cell lines was also analyzed for SHIP1 expression. Compared with the immortalized human bronchial epithelial cell line 16HBE, SHIP1 mRNA and protein expression were notably reduced in NSCLC cell lines (Fig. 1C and D).

SHIPI inhibits NSCLC cell proliferation in vitro and in vivo. To assess SHIP1's biological functions in NSCLC, a SHIP1 inducible plasmid was used to upregulate SHIP1 expression in 3 NSCLC cell lines, and the results demonstrated that SHIP1 mRNA and protein were notably overexpressed in A549 and SPCA-1 cells, but in H1975 cells, only SHIP1 mRNA was notably overexpressed (Fig. 1E); thus, SHIP1-overexpressing A549 and SPCA-1 cells were the appropriate cell models for the following experiments. Cell growth was assessed using MTT assays. These assays demonstrated that the induction of SHIP1 expression from the plasmid significantly inhibited cell viability, compared with cells transfected with control plasmid (Fig. 2A). To clarify the influence of SHIP1 on cell cycle progression, NSCLC cells were grown for $24 \mathrm{~h}$ in serum-free DMEM medium. Subsequently, SHIP1 and control plasmids were separately transfected into NSCLC cells for $48 \mathrm{~h}$. Flow cytometry was used to detect DNA content and demonstrated that the G1/S cell cycle phase transition was significantly inhibited by SHIP1 overexpression in A549 and SPCA-1 cells (Fig. 2B). To determine the effect of SHIP1 on the growth of NSCLC cells in vivo, an in vivo tumorigenesis study was established by inoculating stable SHIP1-overexpressing or control A549 cells into nude mice. Tumor volumes were measured every 3 days, and the growth curves were generated to assess tumor growth rates. A total of 3 weeks after injection, the mice were sacrificed and the tumors were weighed. The tumor growth curves revealed that the tumor growth rate of the SHIP1-overexpression group was notably reduced, compared with the control group. Furthermore, the mean tumor weights of the SHIP1-overexpression group were significantly reduced, compared with the control group 
A

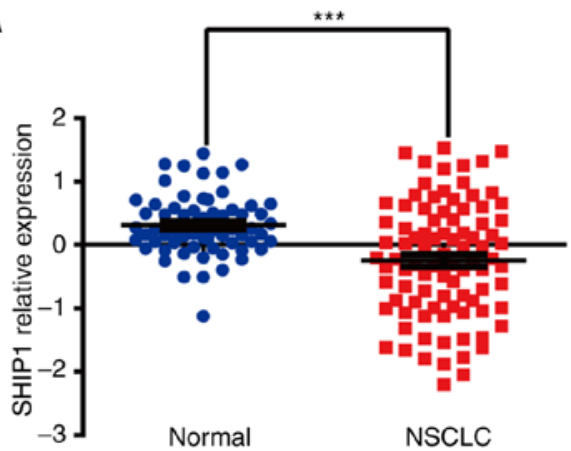

C

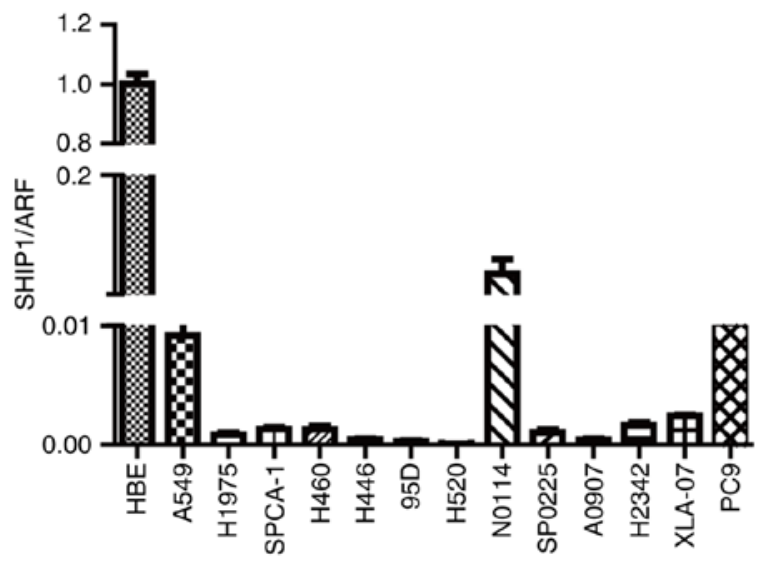

B

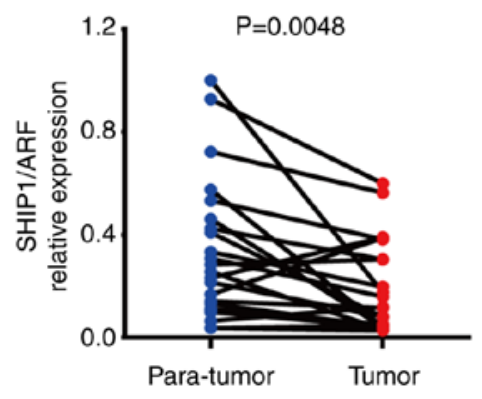

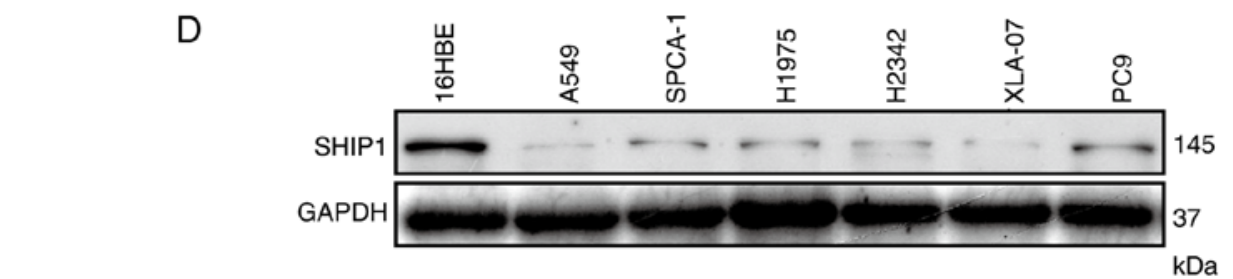

$\mathrm{E}$
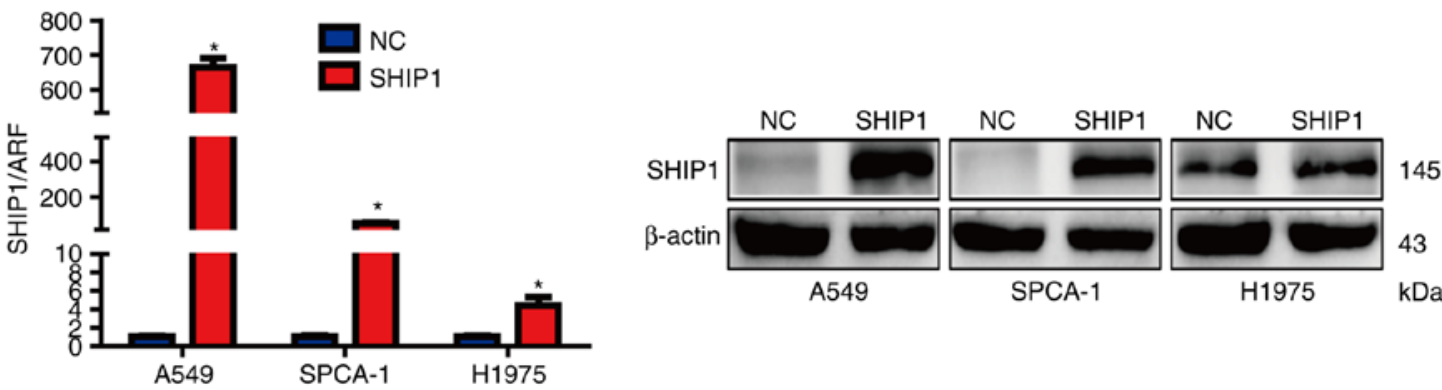

Figure 1. SHIP1 is downregulated in NSCLC. (A) Data extracted from Gene Expression Omnibus GSE19188 revealed that SHP1 has reduced expression levels in NSCLC. Student's t-test, ${ }^{* * *} \mathrm{P}<0.001$. (B) SHIP1 mRNA expression in 26 NSCLC tissues and adjacent normal lung tissues normalized to ARF5. Paired-sample Student's t-test, $\mathrm{P}=0.0048$. (C) SHIP1 mRNA in NSCLC cell lines and an immortalized normal bronchial epithelial cell line (16HBE). (D) SHIP1 protein levels in NSCLC cell lines and an immortalized normal bronchial epithelial cell line (16HBE). (E) SHIP1 mRNA and protein levels in SHIP1-overexpressing NSCLC cells. Bars represent the mean \pm standard deviation. ${ }^{*} \mathrm{P}<0.05$. $\beta$-actin served as an internal control. All of the experiments were repeated at least thrice. SHIP1, Src homology 2-containing inositol-5'-phosphatase 1; NSCLC, non-small cell lung cancer; ARF, ADP ribosylation factor 5; NC, control.

$(1.156 \pm 0.112$ vs. $0.448 \pm 0.122$ g; Fig. 2 C). These results supported the hypothesis that SHIP1 significantly inhibits cell growth in vitro and in vivo.

SHIP1 inhibits NSCLC cell metastasis in vitro and in vivo. To assess the metastasis effect of SHIP1 in NSCLC cells, the Transwell and Boyden chamber assays were used. SHIP1-overexpressing cells and control cells were cultured in a Transwell apparatus or Boyden chambers coated with
Matrigel for $10 \mathrm{~h}$. Subsequently, migrated cells were counted, and the number of migrating cells in the SHIP1-overexpressing group was significantly reduced, compared with the control group (Fig. 3A and B). To further assess the effect of SHIP1 on NSCLC metastasis in vivo, intrahepatic metastasis assays were performed by inoculating stable SHIP1-overexpression or control A549 cells under the liver capsule of mice, and fluorescent image detection was used to confirm intra-hepatic tumor dissemination. Additionally, intra-hepatic dissemination in the 
A

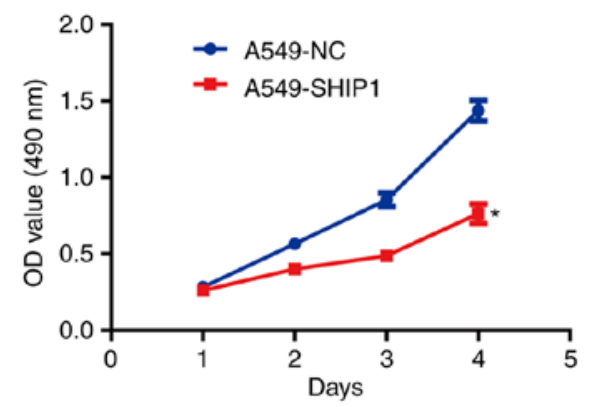

B
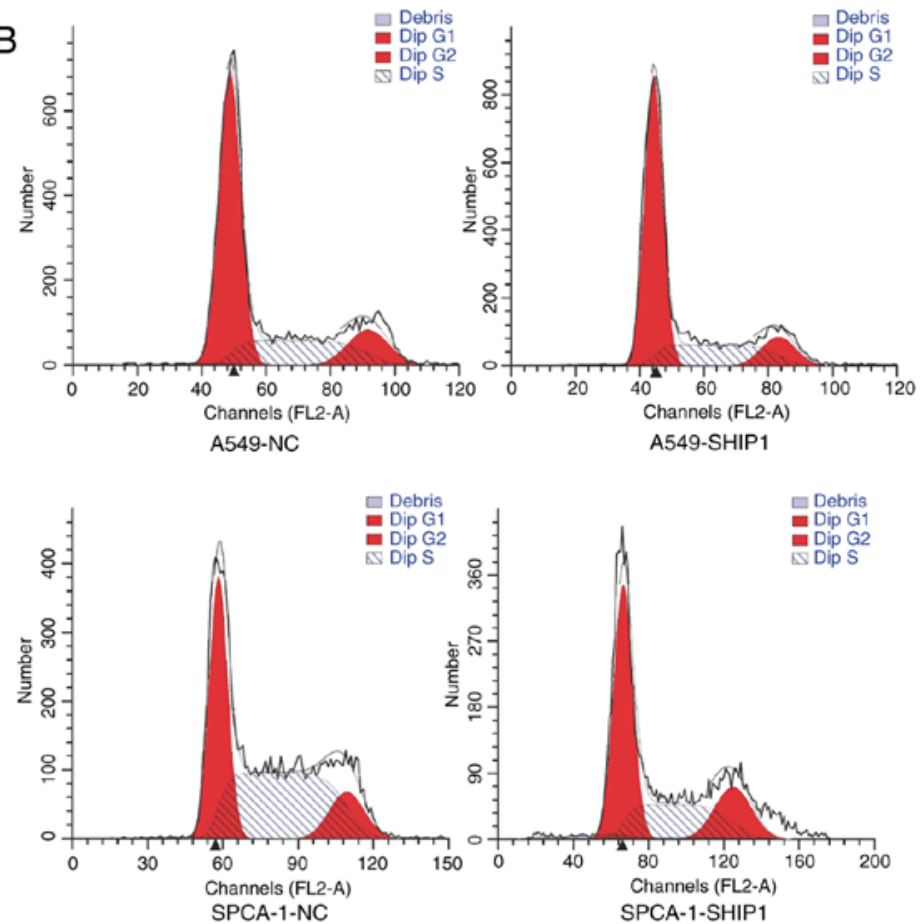

C

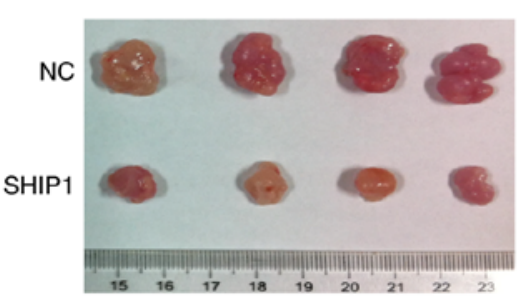

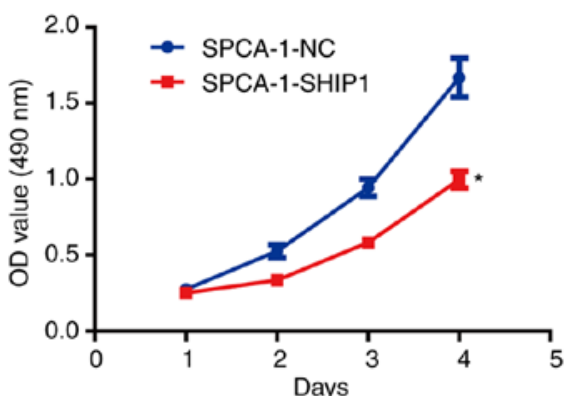

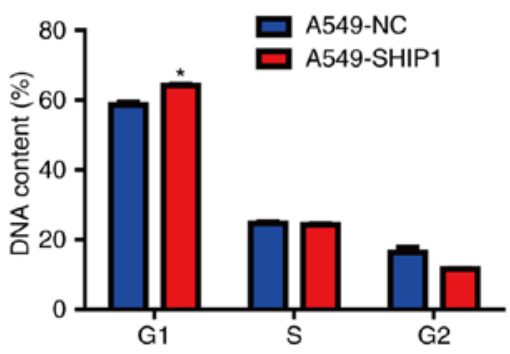

Figure 2. SHIP1 inhibits NSCLC cell proliferation in vitro and in vivo. (A) SHIP1 overexpression reduced NSCLC cell growth in vitro as assessed with an MTT assay. Student's t-test. (B) High SHIP1 expression induced G1/S arrest in NSCLC cells as assessed by flow cytometry. Student's t-test. (C) In vivo tumorigenicity of A549 cells in nude mice was notably inhibited in SHIP1-overexpression cells, compared with control cells ( $\mathrm{n}=6 / \mathrm{group}$ ). All of the experiments were repeated at least thrice. * $\mathrm{P}<0.05$. OD, optical density; SHIP1, Src homology 2-containing inositol-5'-phosphatase 1; NSCLC, non-small cell lung cancer; NC, control.

SHIP1-overexpressing group was notably reduced, compared with the control group (Fig. 3C). The aforementioned results indicate that SHIP1 inhibits NSCLC cell metastasis in vitro and in vivo.

SHIP1 suppresses PI3K/AKT-mediated cell cycle and epithelial-mesenchymal transition (EMT) signals. To further investigate the mechanism by which SHIP1 functions as a tumor suppressor in NSCLC, the protein levels of cell cycle- and EMT-associated genes were examined in SHIP1-overexpression and control cells. Cyclin D1 and
CDK4/6 levels were reduced in SHIP1-overexpression cells, indicating that SHIP1 suppresses the association between cyclin D1 and CDK4/6 (Fig. 4A). The EMT-associated protein E-cadherin was increased in SHIP1-overexpression cells, compared with control cells, whereas N-cadherin and Vimentin levels were downregulated by SHIP1. These results indicate that SHIP1 regulates NSCLC metastasis via EMT-associated proteins (Fig. 4B). Further pathway analysis revealed that SHIP1 overexpression notably reduced $\beta$-catenin and p-AKT levels but not AKT, KRAS, EGFR and p-EGFR levels (Fig. 4C), indicating that as an antagonizer of PI3K 
A

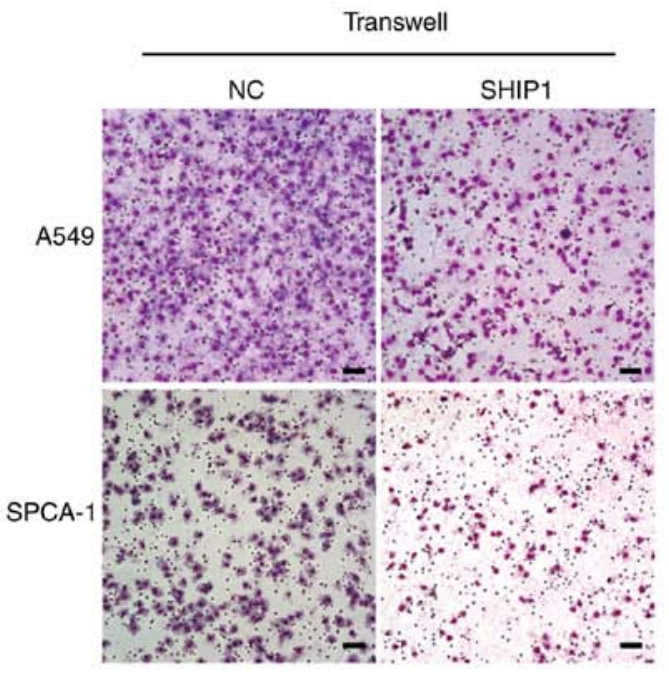

B

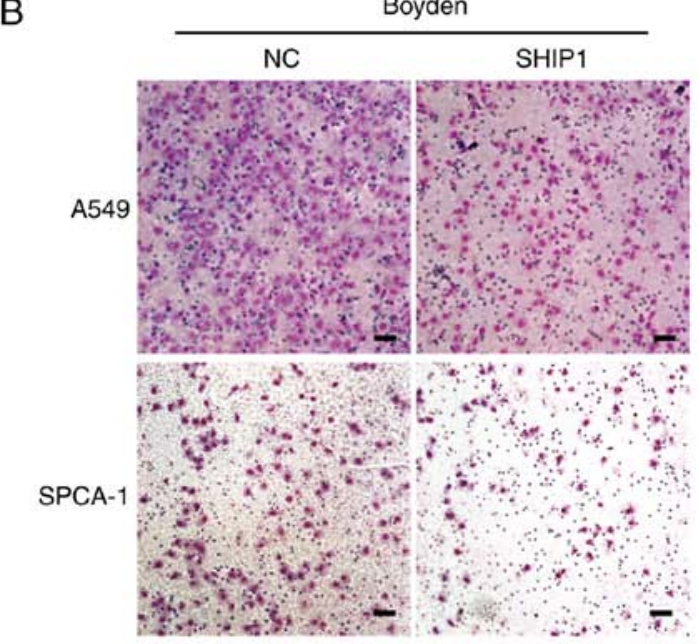

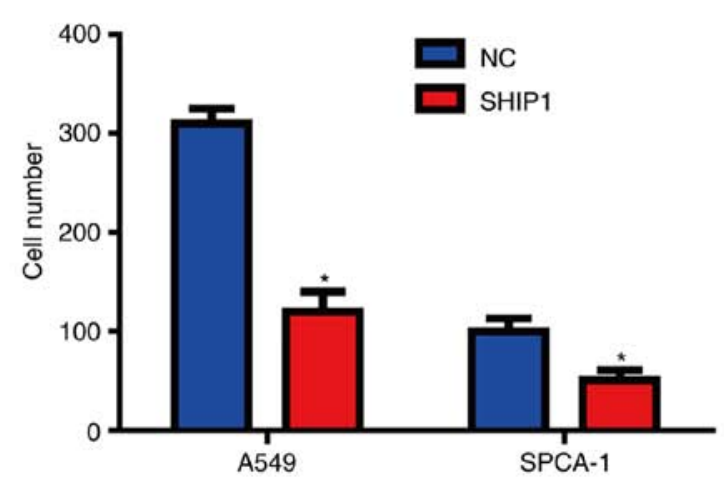

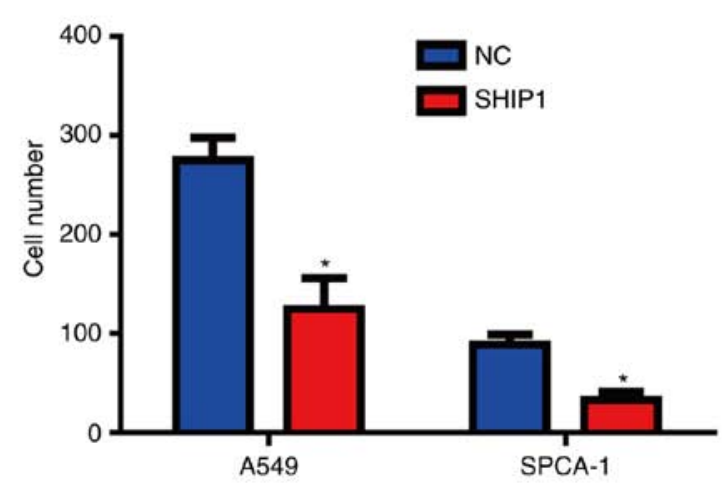

GFP

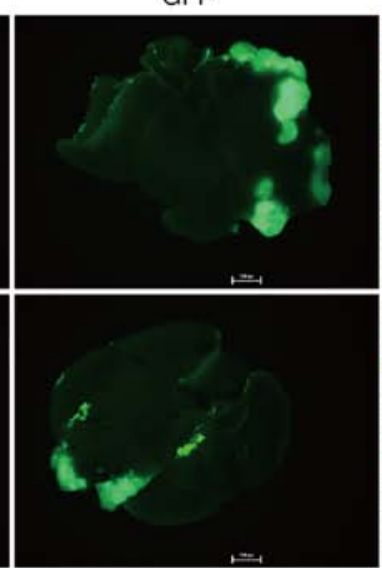

H\&E

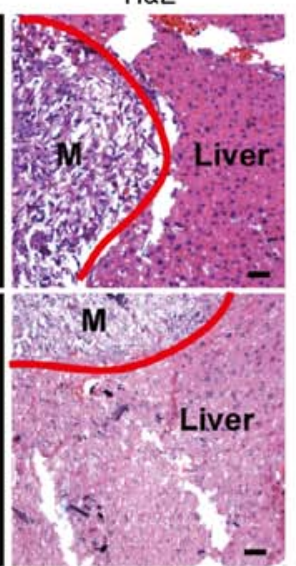

Figure 3. SHIP1 inhibits NSCLC cell metastasis in vitro and in vivo. (A) SHIP1 upregulation reduced NSCLC cell migration in vitro by Transwell assay. Student's t-test, ${ }^{*} \mathrm{P}<0.05$. (B) SHIP1 upregulation reduced NSCLC cell invasion in vitro by Boyden assay. Student's t-test, "P<0.05. (C) Intrahepatic metastasis assays were performed by inoculating stable SHIP1-overexpressing or control A549 cells under the liver capsule of mice, and external optical fluorescence images of liver were obtained 40 days after injection. The livers were observed under a microscope (x1 magnification). Representative images of H\&E staining of metastatic cancer tissues are presented. Scale bars, $25 \mu \mathrm{m}$. Data are presented as the mean \pm standard deviation for 3 independent experiments. M, metastatic cancer tissue; H\&E, hematoxylin and eosin; SHIP1, Src homology 2-containing inositol-5'-phosphatase 1; NSCLC, non-small cell lung cancer; NC, control; GFP, green fluorescence protein.

activity, SHIP1 suppresses PI3K-mediated downstream pathways. Furthermore, $\beta$-catenin, cyclin D1 and CDK6 levels were gradually restored when using EGF to activate the
PI3K/AKT pathway in SHIP1-overexpressing cells (Fig. 4D). Subsequently, LY294002, an inhibitor of the PI3K/AKT pathway, was used to inactivate the PI3K/AKT pathway in 
A

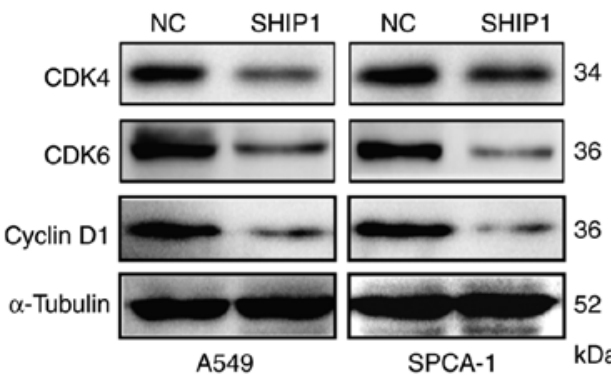

C

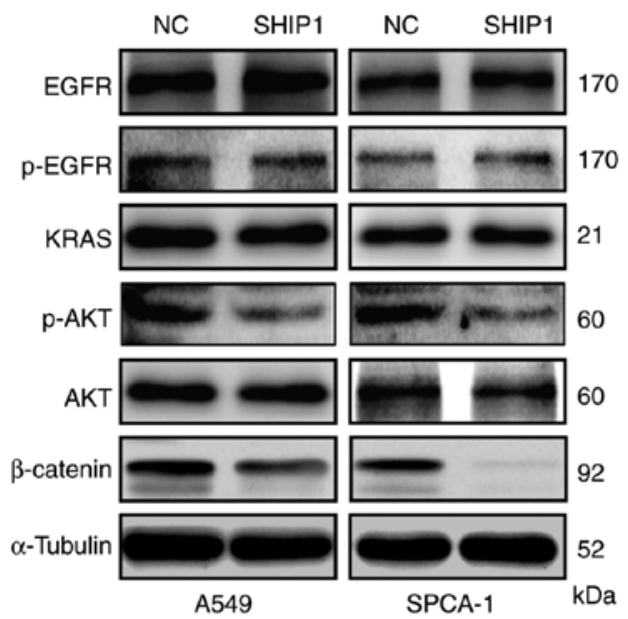

B

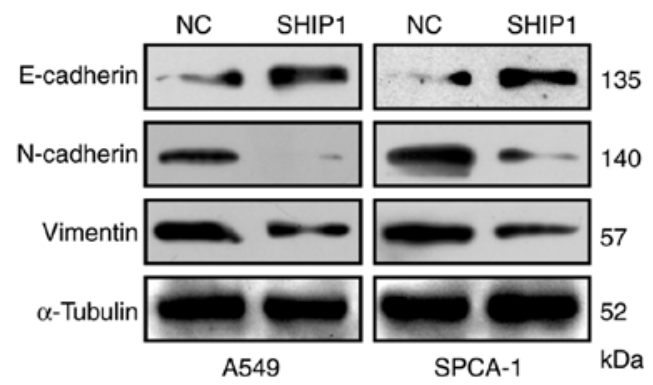

D

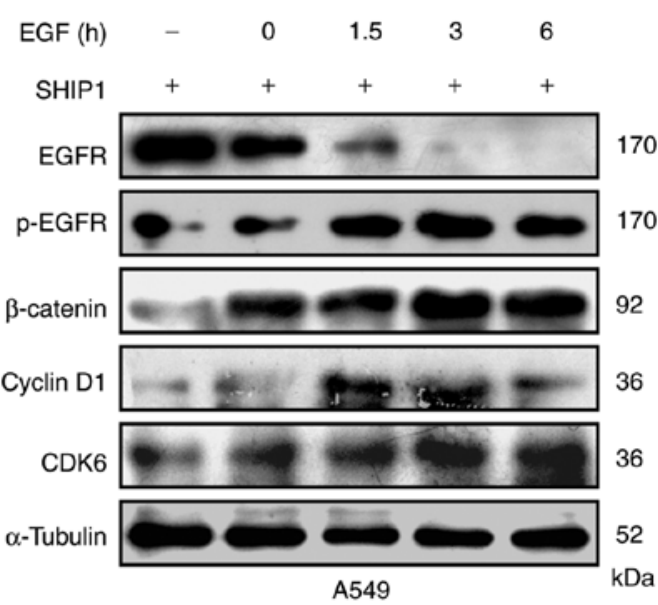

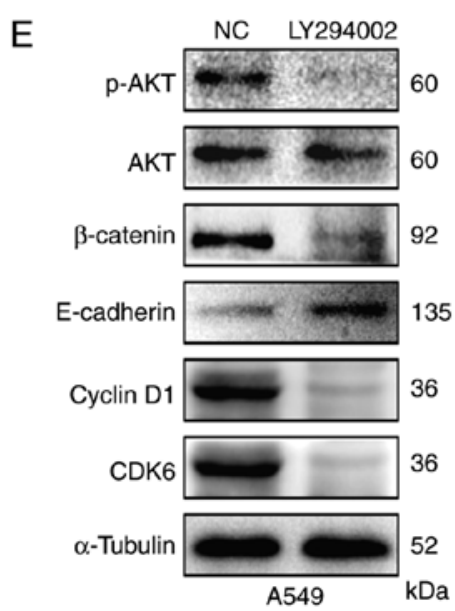

Figure 4. SHIP1 suppresses PI3K/AKT-mediated cell cycle and EMT signals. (A) Expression of the cell cycle-associated proteins cyclin D1, CDK4 and CDK6 in SHIP1-overexpressing NSCLC and control cells. (B) SHIP1 upregulation reduced the expression of EMT-associated proteins, including Vimentin and N-cadherin, and increased the expression of E-cadherin. (C) In NSCLC cells, upregulated SHIP1 inhibited $\beta$-catenin and p-AKT levels, but not EGFR, p-EGFR and KRAS levels. (D) SHIP1-overexpressing A549 cells were treated with EGF (100 ng/ml) for different times to activate EGFR phosphorylation, and cellular EGFR, p-EGFR, $\beta$-catenin, cyclin D1 and CDK6 levels were assessed by western blot analysis. (E) A549 cells were treated with LY294002 to inactivate the PI3K/AKT pathway, and cellular $\beta$-catenin, cyclin D1, CDK6 and E-cadherin levels were assessed by western blot analysis. $\alpha$-Tubulin served as an internal control. All of the experiments were repeated at least thrice. CDK, cyclin dependent kinase; p-, phospho-; EMT, epithelial-mesenchymal transition; PI3K, phosphoinositide 3-kinase; SHIP1, Src homology 2-containing inositol-5'-phosphatase 1; NSCLC, non-small cell lung cancer; NC, control; EGFR, epidermal growth factor receptor.

A549 cells and detect the levels of its downstream cell cycleand EMT-associated factors. The results demonstrated that $\beta$-catenin, cyclin D1, and CDK6 levels were decreased, but the E-cadherin level was increased (Fig. 4E). Collectively, these results indicate that SHIP1 suppresses PI3K/AKT-mediated cell cycle and EMT signals to inhibit cell proliferation and metastasis in NSCLC.

Pathoclinical characteristics of SHIPI expression in NSCLC. Immunohistochemistry was performed to examine SHIP1 protein expression in 146 NSCLC tissues and 59 non-cancerous lung tissues, and significant downregulation of SHIP1 was observed in NSCLC tissues, compared with non-cancerous lung tissues (Fig. 5A and B; Table I). Clinical characteristics associated with SHIP1 were analyzed, revealing that low SHIP1 expression was significantly negatively associated with American Joint Committee on Cancer (AJCC) clinical stage (AJCC 8th stage system) (34) $(\mathrm{P}=0.009)$, T classification $(\mathrm{P}=0.028)$, and $\mathrm{N}$ classification $(\mathrm{P}=0.043)$, but no other clinical features (Table II). Kaplan-Meier survival analysis 
A

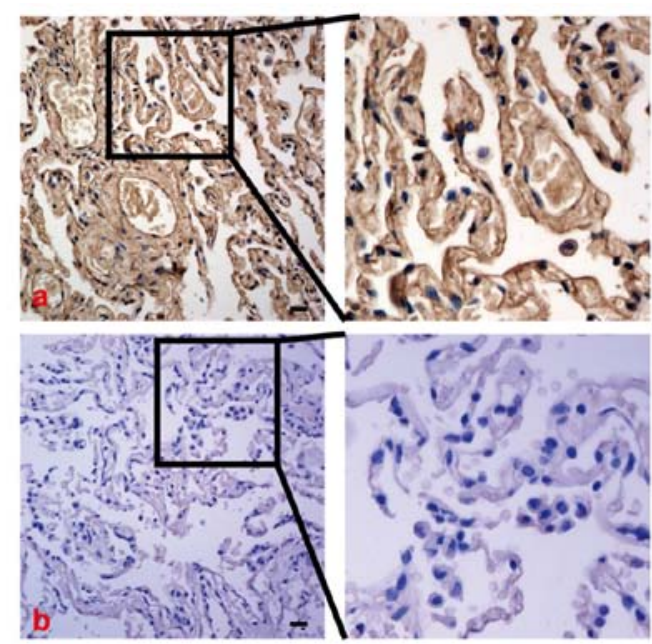

C

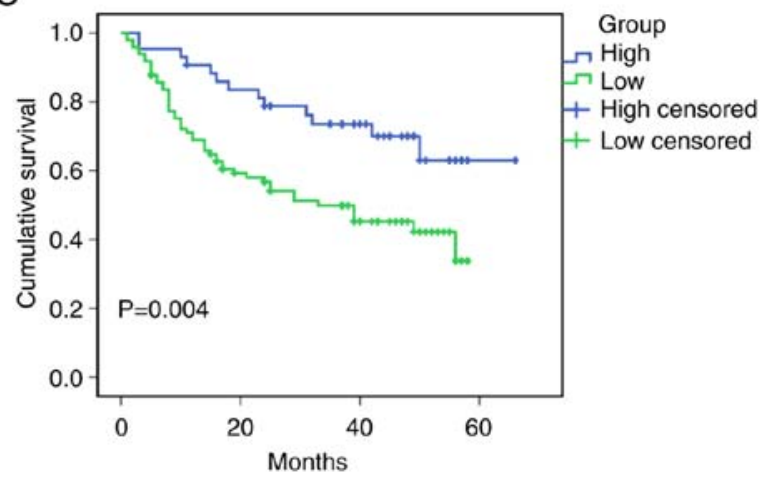

B

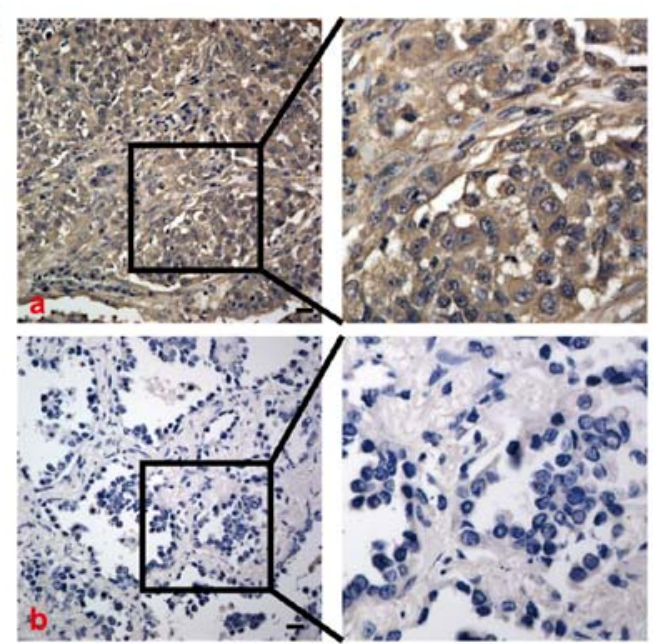

D

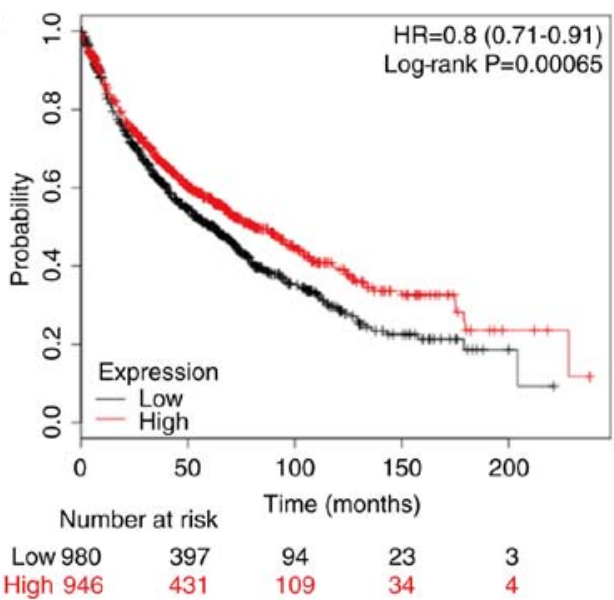

Figure 5. SHIP1 downregulation is an unfavorable factor in NSCLC. (A) Immunohistochemistry staining of SHIP1 in non-cancerous lung tissues. (A-a) Positive SHIP1 staining. (A-b) Negative SHIP1 staining. (B) Immunohistochemistry staining of SHIP1 in NSCLC samples. (B-a) Positive SHIP1 staining. (B-b) Negative SHIP1 staining. (C) Overall survival rates were analyzed by Kaplan-Meier survival analysis in patients with NSCLC based on SHIP1 expression. (D) Overall survival rates were predicted using the Kaplan-Meier plotter database. SHIP1, Src homology 2-containing inositol-5'-phosphatase 1; NSCLC, non-small cell lung cancer.

Table I. The expression of SHIP1 in non-small cell lung cancer, compared with non-cancerous lung tissues.

\begin{tabular}{lcccr}
\hline & & \multicolumn{2}{c}{ SHIP1 expression } & \\
\cline { 3 - 4 } Group & Cases (n) & Negative (\%) & Positive (\%) & P-value \\
\hline Cancer & 146 & $101(69.2)$ & $45(30.8)$ & $<0.001$ \\
Non-cancerous & 59 & $11(18.6)$ & $48(81.4)$ & \\
\hline
\end{tabular}

SHIP1, Src homology 2-containing inositol-5'-phosphatase 1.

revealed that patients with NSCLC with low SHIP1 expression exhibited significantly reduced overall survival rates (Fig. 5C). Consistently, the prediction analysis of microarrays and constructed Kaplan-Meier plots from Kaplan-Meier Plotter database (http://kmplot.com/analysis/index. php?cancer $=$ lung\&p=service) also revealed similar overall survival rates (Fig. 5D).

Further univariate and multivariate Cox regression analyses were performed to assess independent prognostic factors in patients with NSCLC. It was observed that SHIP1 expression levels and AJCC stage were significantly associated with overall survival rate. Patients with low SHIP1 levels exhibited significantly reduced survival, compared with patients with high levels, and patients with advanced AJCC stage exhibited significantly reduced survival, compared with those with early stage disease (Table III). Collectively, these observations indicate that low SHIP1 expression is a negative prognostic factor in NSCLC.

The SHIP1 promoter lacks methylation sites. Emerging research indicates that hypermethylation of $\mathrm{CpG}$ islands in 
Table II. Association between the clinicopathologic factors and expression of SHIP1 in non-small cell lung cancer.

\begin{tabular}{|c|c|c|c|c|}
\hline \multirow[b]{2}{*}{ Factors } & \multirow[b]{2}{*}{$\mathrm{n}$} & \multicolumn{2}{|c|}{ SHIP1 expression } & \multirow[b]{2}{*}{ P-value } \\
\hline & & Negative (n) & Positive (n) & \\
\hline Sex & & & & 0.661 \\
\hline Male & 101 & $71(70.3 \%)$ & $30(29.7 \%)$ & \\
\hline Female & 45 & $30(66.7 \%)$ & $15(33.3 \%)$ & \\
\hline Age (years) & & & & 0.512 \\
\hline$\leq 60$ & 71 & $48(67.6 \%)$ & $23(32.4 \%)$ & \\
\hline$>60$ & 73 & $53(72.6 \%)$ & $20(27.4 \%)$ & \\
\hline Unknown & 2 & 0 & 2 & \\
\hline Pathology & & & & 0.708 \\
\hline Squamous carcinoma & 78 & $55(70.5 \%)$ & $23(29.5 \%)$ & \\
\hline Adenocarcinoma & 68 & $46(67.6 \%)$ & $22(32.4 \%)$ & \\
\hline $\mathrm{T}$ classification ${ }^{\mathrm{b}}$ & & & & $0.028^{\mathrm{a}}$ \\
\hline $\mathrm{T}_{1}$ & 23 & $11(47.8 \%)$ & $12(52.2 \%)$ & \\
\hline $\mathrm{T}_{2}$ & 103 & $72(69.9 \%)$ & $31(30.1 \%)$ & \\
\hline $\mathrm{T}_{3}$ & 18 & $16(88.9 \%)$ & $2(11.1 \%)$ & \\
\hline $\mathrm{T}_{4}$ & 2 & $2(100 \%)$ & 0 & \\
\hline $\mathrm{N}$ classification ${ }^{\mathrm{b}}$ & & & & $0.043^{\mathrm{a}}$ \\
\hline $\mathrm{N}_{0}$ & 63 & $38(60.3 \%)$ & $25(39.7 \%)$ & \\
\hline $\mathrm{N}_{1}+\mathrm{N}_{2}+\mathrm{N}_{3}$ & 83 & $63(75.9 \%)$ & $20(24.1 \%)$ & \\
\hline Clinical stage ${ }^{\mathrm{b}}$ & & & & $0.009^{\mathrm{a}}$ \\
\hline I & 33 & $18(54.5 \%)$ & $15(45.5 \%)$ & \\
\hline II & 88 & $60(68.2 \%)$ & $28(31.8 \%)$ & \\
\hline III & 25 & $23(92 \%)$ & $2(8 \%)$ & \\
\hline
\end{tabular}

${ }^{\mathrm{a}} \mathrm{P}<0.05 .{ }^{\mathrm{b}}$ American Joint Committee on Cancer 8th stage system (34). SHIP1, Src homology 2-containing inositol-5'-phosphatase 1.

Table III. The univariate and multivariate Cox regression analysis of overall survival time.

\begin{tabular}{|c|c|c|c|c|c|c|}
\hline \multirow[b]{2}{*}{ Factors } & \multicolumn{3}{|c|}{ Univariate analysis } & \multicolumn{3}{|c|}{ Multivariate analysis } \\
\hline & P-value & HR & $95 \% \mathrm{CI}$ & P-value & HR & $95 \% \mathrm{CI}$ \\
\hline \multicolumn{7}{|l|}{ Sex } \\
\hline Male vs. female & 0.407 & 1.322 & $0.683-2.557$ & - & - & - \\
\hline \multicolumn{7}{|l|}{ Age (years) } \\
\hline$\leq 60$ vs. $>60$ & 0.546 & 1.172 & $0.701-1.960$ & - & - & - \\
\hline \multicolumn{7}{|l|}{$\mathrm{T}_{\text {classification }}{ }^{\mathrm{b}}$} \\
\hline $\mathrm{T}_{1}+\mathrm{T}_{2}$ vs. $\mathrm{T}_{3}+\mathrm{T}_{4}$ & 0.789 & 0.923 & $0.511-1.665$ & - & - & - \\
\hline \multicolumn{7}{|l|}{$\mathrm{N}$ classification ${ }^{\mathrm{b}}$} \\
\hline $\mathrm{N}_{0}$ vs. $\mathrm{N}_{1}+\mathrm{N}_{2}+\mathrm{N}_{3}$ & 0.923 & 1.022 & $0.655-1.595$ & - & - & - \\
\hline \multicolumn{7}{|l|}{ Pathology $\mathrm{y}^{\mathrm{b}}$} \\
\hline $\begin{array}{l}\text { Squamous carcinoma } \\
\text { vs. adenocarcinoma }\end{array}$ & $<0.001^{\mathrm{a}}$ & 0.313 & $0.167-0.586$ & $<0.001^{\mathrm{a}}$ & 0.345 & 0.196-0.606 \\
\hline \multicolumn{7}{|l|}{ Stage $^{b}$} \\
\hline I+II vs. III & $<0.001^{\mathrm{a}}$ & 3.692 & $1.783-7.644$ & $<0.001^{\mathrm{a}}$ & 3.515 & $2.176-5.678$ \\
\hline \multicolumn{7}{|l|}{ SHIP1 expression } \\
\hline Positive vs. negative & $0.008^{\mathrm{a}}$ & 2.361 & $1.255-4.444$ & $0.007^{\mathrm{a}}$ & 2.352 & $1.262-4.384$ \\
\hline
\end{tabular}

${ }^{\mathrm{a} P}<0.05 .{ }^{\mathrm{b}}$ American Joint Committee on Cancer 8th stage system (34). HR, hazard ratio; CI, confidence interval; SHIP1, Src homology 2-containing inositol-5'-phosphatase 1. 
A

A Observed vs. expression

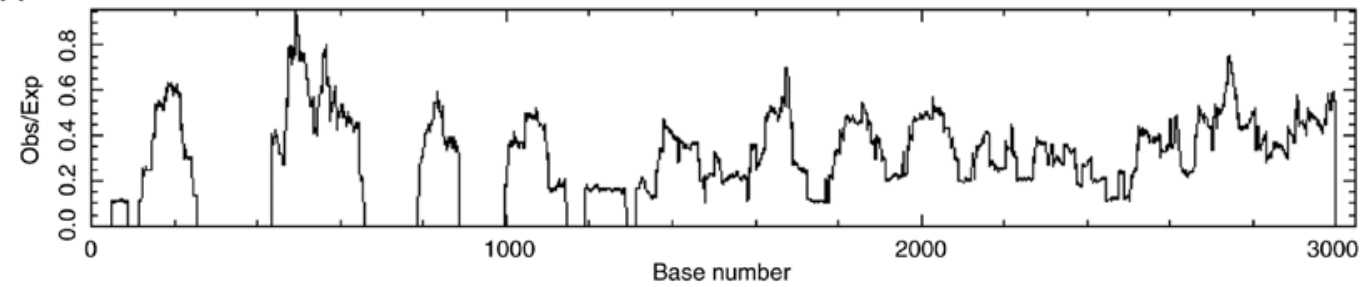

B

Percentage
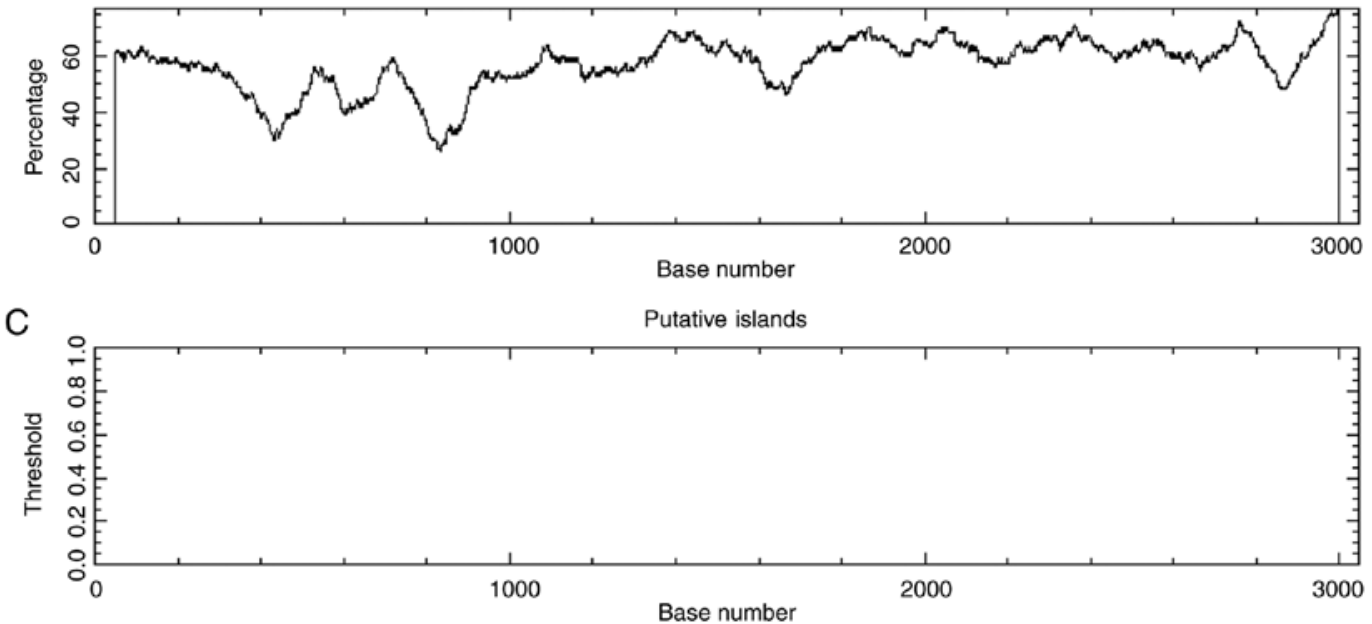

Figure 6. The SHIP1 promoter lacks methylation sites. (A) The ratio of $\mathrm{CpG}_{\text {obs }} / \mathrm{CpG}_{\text {exp }}\left(\mathrm{CpG}_{\text {observed }} / \mathrm{CpG}_{\text {expected }}\right)$ in the SHIP1 promoter based on the EMBOSS Cpgplot database. (B) The content of $(\mathrm{G}+\mathrm{C})(\% \mathrm{GC})$ in the SHIP1 promoter was predicted using the EMBOSS Cpgplot database. (C) CpG islands in the SHIP1 promoter were predicted using the EMBOSS Cpgplot database. SHIP1, Src homology 2-containing inositol-5'-phosphatase 1.

gene promoters frequently results in transcriptional silencing of genes (35). To analyze whether low SHIP1 expression results from SHIP1 promoter methylation, bioinformatics was used to predict $\mathrm{CpG}$ islands in the SHIP1 promoter. $\mathrm{CpG}$ islands are defined as sequences $>200 \mathrm{bp}$ in length with $\mathrm{a}(\mathrm{G}+\mathrm{C})(\% \mathrm{GC})$ content $>50 \%$ and a ratio of $\mathrm{CpG}$ dinucleotide frequencies $\left(\mathrm{CpG}_{\mathrm{obs}} / \mathrm{CpG}_{\text {exp }}\right)>0.6$ (36). EMBOSS Cpgplot (http://www.ebi.ac.uk/Tools/seqstats/emboss_cpgplot/) results predicted that no $\mathrm{CpG}$ islands were observed in the SHIP1 promoter (Fig. 6A-C), indicating that reduced SHIP1 expression in NSCLC is not associated with its promoter methylation.

Reduced SHIPI expression is not associated with EGFR or KRAS mutations. To analyze the association between SHIP1 expression and EGFR/KRAS mutations in NSCLC, the gene expression signature of 83 matched pairs of lung adenocarcinomas and non-malignant adjacent tissue from GSE75037 were analyzed using Illumina WG6-V3 expression arrays. SHIP1 gene expression information was extracted and it was determined that the SHIP1 gene has significantly reduced expression in lung adenocarcinomas tissues, compared with non-malignant adjacent tissues (Fig. 7A). SHIP1 expression is progressively lost during tumor progression (Fig. 7B). Additionally, the association between SHIP1 expression and EGFR/KRAS mutations was further analyzed and it was determined that no significant differences were observed between the EGFR/KRAS-mutated tissues and wild-type tissues (Fig. 7C-E). Collectively, these results indicated that reduced SHIP1 expression is not associated with EGFR or KRAS mutations in NSCLC.

\section{Discussion}

The aberrant expression of SHIP1 has been observed in various diseases, including malignant tumors (11-14). The investigation of SHIP1 in tumors is limited to hematological tumors, where SHIP1 was identified as a suppressor of the occurrence and development of hematological tumors by inhibiting hematopoietic cell proliferation and metastasis (15). SHIP1 downregulation was observed in acute myeloid leukemia and associated with poor survival rates (9). However, the role of SHIP1 in solid tumors remains poorly understood.

As the leading cause of cancer-associated mortalities globally, according to the epidemiological report published in 2018 (20), lung cancer has been a hotly pursued area of cancer research. However, the expression and roles of SHIP1 in NSCLC remain unclear. In the present study, it was determined that SHIP1 gene expression was reduced in NSCLC tissues, compared with normal lung tissues, based on GEO database analysis. Furthermore, SHIP1 levels are progressively reduced during tumor progression. Additionally, RT-qPCR and western blot analysis also revealed that SHIP1 mRNA and protein levels were reduced in NSCLC tissues and cell lines. These results strongly support the hypothesis that SHIP1 serves a vital role in NSCLC.

Functional analysis revealed that SHIP1 inhibits cell proliferation, invasion and migration of NSCLC in vitro and in vivo. Furthermore, flow cytometry detection revealed G1-S phase arrest upon SHIP1 overexpression. Mechanistically, reductions in G1-S phase-associated proteins cyclin D1, CDK4 and CDK6, and EMT-associated proteins N-cadherin and 
A

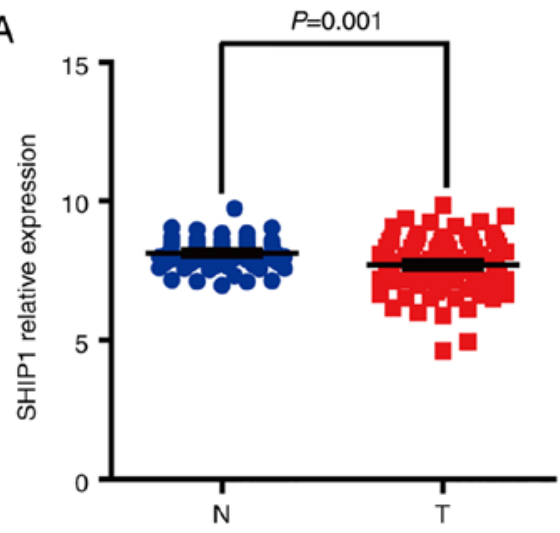

C

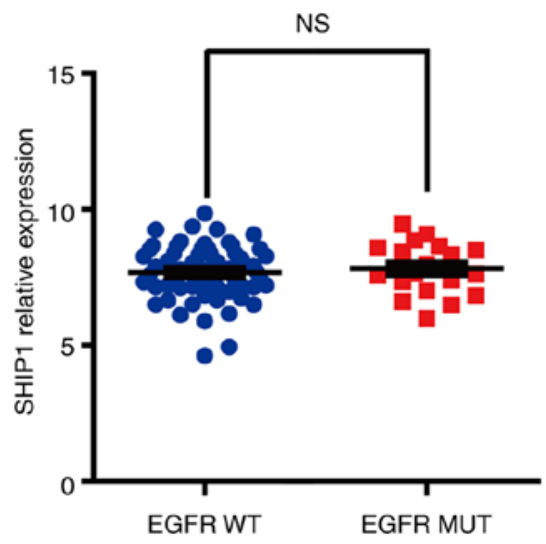

E

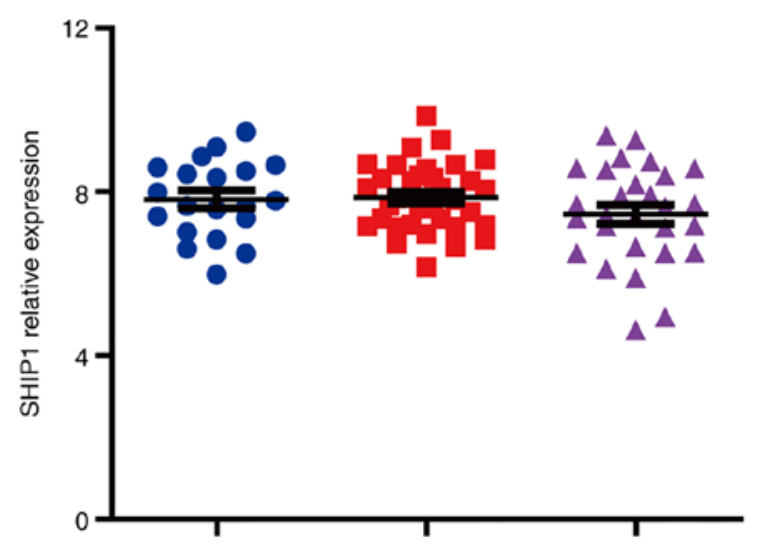

B

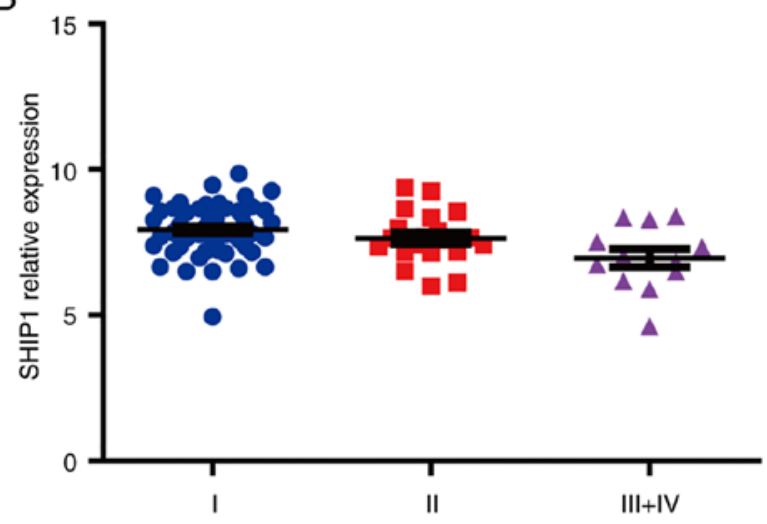

D

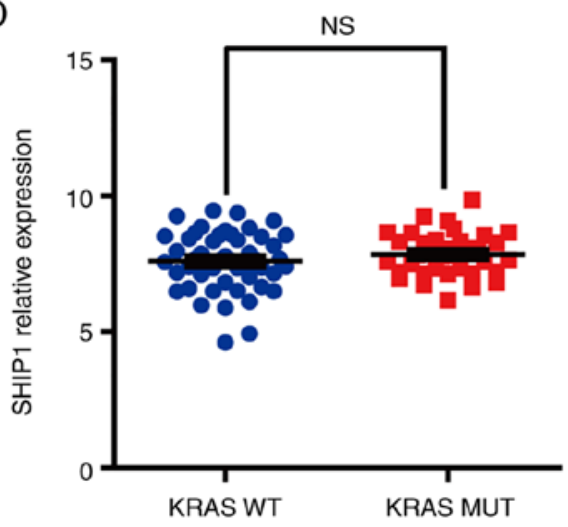

Figure 7. SHIP1 downregulation is not associated with EGFR or KRAS mutations. (A) SHIP1 gene expression was analyzed in 83 matched pairs of lung adenocarcinoma and non-malignant adjacent tissues from Gene Expression Omnibus GSE75037. Paired-sample Student's t-test, P=0.001. (B) SHIP1 expression is progressively lost during tumor progression with American Joint Committee on Cancer 8th stage system (34). One-way ANOVA, P=0.0052; Dunnett-t test ( $\mathrm{P}=0.0491$ for I vs. II; $\mathrm{P}=0.0335$ for II vs. III+IV). (C) The association between SHIP1 expression and EGFR mutations. Student's t-test, P>0.05. (D) The association between SHIP1 expression and KRAS mutations. Student's t-test, P $>0.05$. (E) The association between SHIP1 expression and EGFR or KRAS mutations. One-way ANOVA, P $>0.05$. ANOVA, analysis of variance; KRAS, Kirsten rat sarcoma; EGFR, epidermal growth factor receptor; NS, not significant; WT, wild-type; MT, mutated; SHIP1, Src homology 2-containing inositol-5'-phosphatase 1; N, normal; T, tumor.

Vimentin were observed in SHIP1-overexpression NSCLC cells, whereas the EMT antagonistic factor E-cadherin was increased. The cell cycle and EMT are the key pathways involved in tumor cell growth and metastasis $(37,38)$. These results demonstrated that SHIP1 inhibits cell proliferation and metastasis via cell cycle- and EMT-associated proteins.

The PI3K/AKT pathway is a key signal mediator during cell cycle transitions (39) and promotes the progression of the EMT (26). As an antagonist of PI3K activity (15), SHIP1 suppresses PI3K-mediated downstream pathways by dephosphorylating the key PI3K-generated secondary messenger in hematological tumors and a number of non-malignant diseases, including acute myelocytic leukemia and diabetic kidney disease $(9,13)$. In the present study, it was determined that $\beta$-catenin and p-AKT levels, but not AKT, KRAS, EGFR and $\mathrm{p}$-EGFR levels, were reduced in SHIP1-overexpressing NSCLC cells, indicating that PI3K/AKT are downstream factors of SHIP1. Furthermore, EGF was used to activate the PI3K/AKT pathway in SHIP1-overexpressing NSCLC cells, and it was determined that $\beta$-catenin, cyclin D1 and CDK6 
levels were restored. These data support the hypothesis that SHIP1 dephosphorylates the key PI3K-generated secondary messenger to inactivate the PI3K/AKT pathway, and the downstream cell cycle and EMT pathway, ultimately inducing the inhibition of cell growth and metastasis in NSCLC.

Previous studies reported that SHIP1 levels were significantly reduced in acute myeloid leukemia tissues and has been implicated as a suppressor of hematopoietic transformation (40), but the association between SHIP1 expression and pathoclinical characteristics of hematopoietic tumors remains unclear. In the present study, it was observed that SHIP1 was negatively associated with AJCC clinical stage, T classification and $\mathrm{N}$ classification. Notably, low SHIP1 expression acts as a negative prognostic factor in patients with NSCLC.

As an important modification of proteins and nucleic acids, methylation of $\mathrm{CpG}$ islands in gene promoters frequently results in silencing of suppressor genes (41). The methylation rates of the $\mathrm{CpG}$ sites in the upstream region of SHIP1 exon 1 did not significantly differ between Alzheimer's disease and control subjects (42). However, SHIP1 promoter methylation levels were not reported. In the present study, bioinformatics was used to predict $\mathrm{CpG}$ islands in the SHIP1 promoter and it was determined that the SHIP1 promoter lacks CpG islands, indicating that the reduced expression of SHIP1 in NSCLC was not associated with the methylation of its promoter.

EGFR and KRAS mutations are frequently exhibited in patients with NSCLC, particularly in patients with lung adenocarcinoma (43). EGFR-TKIs have become a key treatment for patients with NSCLC with different EGFR mutations (44); however, drug resistance is becoming increasingly prominent (22). Recent research has identified the dysregulation ofdownstreampathways, including lossof suppressors, as a mechanism of resistance (23). In the present study, the association between SHIP1 expression and EGFR/KRAS mutations was analyzed in NSCLC and it was determined that reduced SHIP1 expression was not associated with EGFR or KRAS mutations in NSCLC.

The present data demonstrated that SHIP1 is suppressed in NSCLC and inhibits cell proliferation, migration, invasion and tumorigenicity via the PI3K/AKT pathway. Furthermore, the downregulation of SHIP1 exhibits no notable association with EGFR and KRAS mutations. Thus, SHIP1 may be considered as a tumor suppressor, and low SHIP1 expression is a poor prognostic factor in NSCLC.

\section{Acknowledgements}

Not applicable.

\section{Funding}

The present study was supported by the China Postdoctoral Science Foundation (grant no. 2017M613008), the National Natural Science Foundation of China and Yunnan Joint Foundation (grant nos. U1502222, 81702295, 81602029 and 81660389), the Applied Basic Science Research Foundation of Yunnan Province (grant nos. 2017FB12 and 2017FB127) and the Application of genomic technology based early diagnosis and treatment of Qujing Xuanwei Lung Cancer (grant no. 2016RA037).

\section{Availability of data and material}

Not applicable.

\section{Authors' contributions}

QF, YH, CG, ZL, HT, QL, YW and GY performed the research. XS and WF designed the research study. HL, RL, $\mathrm{XT}$ and YX performed the statistical analysis. QF, YH, WF and XS wrote the paper. CG, ZL, HT and QL collected the clinical specimens. YW, GY, HL, RL, XT and YX performed the database analysis. All authors have read and approved the final manuscript.

\section{Ethics approval and consent to participate}

The tissues were approved by the Ethics Committees of the Third Affiliated Hospital of Kunming Medical University. Informed consent was obtained from patients.

\section{Patient consent for publication}

Patients provided informed consent for publication.

\section{Competing interests}

The authors declare that they have no competing interests.

\section{References}

1. Conduit SE, Ramaswamy V, Remke M, Watkins DN, Wainwright BJ, Taylor MD, Mitchell CA and Dyson JM: A compartmentalized phosphoinositide signaling axis at cilia is regulated by INPP5E to maintain cilia and promote Sonic Hedgehog medulloblastoma. Oncogene 36: 5969-5984, 2017.

2. D'Oria R, Laviola L, Giorgino F, Unfer V, Bettocchi S and Scioscia M: PKB/Akt and MAPK/ERK phosphorylation is highly induced by inositols: Novel potential insights in endothelial dysfunction in preeclampsia. Pregnancy Hypertension 10: 107-112, 2017.

3. Tang F, Wang Y, Hemmings BA, Ruegg C and Xue G: $\mathrm{PKB} / \mathrm{Akt}$-dependent regulation of inflammation in cancer. Semin Cancer Biol 48: 62-69, 2018.

4. Wang $\mathrm{H}$ and Shears SB: Structural features of human inositol phosphate multikinase rationalize its inositol phosphate kinase and phosphoinositide 3-kinase activities. J Biol Chem 292: 18192-18202, 2017.

5. Chacko GW, Tridandapani S, Damen JE, Liu L, Krystal G and Coggeshall KM: Negative signaling in B lymphocytes induces tyrosine phosphorylation of the 145-kDa inositol polyphosphate 5-phosphatase, SHIP. J Immunol 157: 2234-2238, 1996.

6. Damen JE, Liu L, Rosten P, Humphries RK, Jefferson AB, Majerus PW and Krystal G: The $145-\mathrm{kDa}$ protein induced to associate with Shc by multiple cytokines is an inositol tetraphosphate and phosphatidylinositol 3,4,5-triphosphate 5-phosphatase. Proc Natl Acad Sci USA 93: 1689-1693, 1996.

7. Geier SJ, Algate PA, Carlberg K, Flowers D, Friedman C, Trask B and Rohrschneider LR: The human SHIP gene is differentially expressed in cell lineages of the bone marrow and blood. Blood 89: 1876-1885, 1997.

8. Veillette A, Latour S and Davidson D: Negative regulation of immunoreceptor signaling. Ann Rev Immunol 20: 669-707, 2002.

9. Täger M, Horn S, Latuske E, Ehm P, Schaks M, Nalaskowski M, Fehse B, Fiedler W, Stocking C, Wellbrock J, et al: SHIP1, but not an AML-derived SHIP1 mutant, suppresses myeloid leukemia growth in a xenotransplantation mouse model. Gene Therapy 24 : 749-753, 2017.

10. Brooks R, Fuhler GM, Iyer S, Smith MJ, Park MY, Paraiso KH, Engelman RW and Kerr WG: SHIP1 inhibition increases immunoregulatory capacity and triggers apoptosis of hematopoietic cancer cells. J Immunol 184: 3582-3589, 2010. 
11. McKeever PM, Kim T, Hesketh AR, MacNair L, Miletic D Favrin G, Oliver SG, Zhang Z, St George-Hyslop P and Robertson J: Cholinergic neuron gene expression differences captured by translational profiling in a mouse model of Alzheimer's disease. Neurobiol Aging 57: 104-119, 2017.

12. Ngoh EN, Weisser SB, Lo Y, Kozicky LK, Jen R, Brugger HK Menzies SC, McLarren KW, Nackiewicz D, van Rooijen N, et al: Activity of SHIP, which prevents expression of interleukin $1 \beta$, is reduced in patients with Crohn's disease. Gastroenterology 150: 465-476, 2016.

13. Li F, Li L, Cheng M, Wang X, Hao J, Liu S and Duan H: SHIP, a novel factor to ameliorate extracellular matrix accumulation via suppressing PI3K/Akt/CTGF signaling in diabetic kidney disease. Biochem Biophys Res Commun 482: 1477-1483, 2017.

14. Chen Z, Shojaee S, Buchner M, Geng H, Lee JW, Klemm L, Titz B, Graeber TG, Park E, Tan YX, et al: Signalling thresholds and negative B-cell selection in acute lymphoblastic leukaemia. Nature 521: 357-361, 2015.

15. Kerr WG: Inhibitor and activator: Dual functions for SHIP in immunity and cancer. Ann NY Acad Sci 1217: 1-17, 2011

16. Janku F: Phosphoinositide 3-kinase (PI3K) pathway inhibitors in solid tumors: From laboratory to patients. Cancer Treatment Rev 59: 93-101, 2017.

17. Viernes DR, Choi LB, Kerr WG and Chisholm JD: Discovery and development of small molecule SHIP phosphatase modulators. Med Res Rev 34: 795-824, 2014.

18. Marion F, Williams DE, Patrick BO, Hollander I, Mallon R, Kim SC, Roll DM, Feldberg L, Van Soest R and Andersen RJ: Liphagal, a Selective inhibitor of PI3 kinase alpha isolated from the sponge Aka coralliphaga: Structure elucidation and biomimetic synthesis. Org Lett 8: 321-324, 2006.

19. Catimel B, Yin MX, Schieber C, Condron M, Patsiouras H, Catimel J, Robinson DE, Wong LS, Nice EC, Holmes AB, et al: PI(3,4,5)P3 interactome. J Proteome Res 8: 3712-3726, 2009.

20. Siegel RL, Miller KD and Jemal A: Cancer statistics, 2018. CA Cancer J Clin 68: 7-30, 2018.

21. Walter AO, Sjin RT, Haringsma HJ, Ohashi K, Sun J, Lee K, Dubrovskiy A, Labenski M, Zhu Z, Wang Z, et al: Discovery of a mutant-selective covalent inhibitor of EGFR that overcomes T790M-mediated resistance in NSCLC. Cancer Discov 3 : 1404-1415, 2013

22. Passiglia F, Listi A, Castiglia M, Perez A, Rizzo S, Bazan V and Russo A: EGFR inhibition in NSCLC: New findings.... and opened questions? Crit Rev Oncol Hematol 112: 126-135, 2017.

23. Morgillo F, Della Corte CM, Fasano M and Ciardiello F: Mechanisms of resistance to EGFR-targeted drugs: Lung cancer. ESMO Open 1: e000060, 2016.

24. Krystal G: Lipid phosphatases in the immune system. Semin Immunol 12: 397-403, 2000.

25. Leslie NR,Biondi RM and Alessi DR: Phosphoinositide-regulated kinases and phosphoinositide phosphatases. Chem Rev 101: 2365-2380, 2001.

26. Fu Q, Song X, Liu Z, Deng X, Luo R, Ge C, Li R, Li Z, Zhao M, Chen Y, et al: miRomics and proteomics reveal a miR-296-3p/PRKCA/FAK/Ras/c-Myc feedback loop modulated by HDGF/DDX $5 / \beta$-catenin complex in lung adenocarcinoma. Clin Cancer Res 23: 6336-6350, 2017.

27. Livak KJ and Schmittgen TD: Analysis of relative gene expression data using real-time quantitative PCR and the $2^{-\Delta \Delta C_{\mathrm{T}}}$ method. Methods 25: 402-408, 2001.

28. Fu QF, Liu Y, Fan Y, Hua SN, Qu HY, Dong SW, Li RL, Zhao MY, Zhen Y, Yu XL, et al: Alpha-enolase promotes cell glycolysis, growth, migration, and invasion in non-small cell lung cancer through FAK-mediated PI3K/AKT pathway. J Hematol Oncol 8: 22,2015 .
29. Wang H, Wu Q, Liu Z, Luo X, Fan Y, Liu Y, Zhang Y, Hua S, Fu Q, Zhao M, et al: Downregulation of FAP suppresses cell proliferation and metastasis through PTEN/PI3K/AKT and Ras-ERK signaling in oral squamous cell carcinoma. Cell Death Dis 5: e1155, 2014

30. Liu Z, Luo W, Zhou Y, Zhen Y, Yang H, Yu X, Ye Y, Li X, Wang H, Jiang Q, et al: Potential tumor suppressor NESG1 as an unfavorable prognosis factor in nasopharyngeal carcinoma. PLoS One 6: e27887, 2011.

31. Zhen Y, Fang W, Zhao M, Luo R, Liu Y, Fu Q, Chen Y, Cheng C, Zhang Y and Liu Z: miR-374a-CCND1-pPI3K/AKT-c-JUN feedback loop modulated by PDCD4 suppresses cell growth, metastasis, and sensitizes nasopharyngeal carcinoma to cisplatin. Oncogene 36: 275-285, 2017.

32. Philipsen S: Expression data for early stage NSCLC. https://www.ncbi.nlm.nih.gov/geo/query/acc.cgi?acc=GSE19188. 2010. Retrieve date: April 10, 2018.

33. Gazdar A, Girard L, Stephen L, Wan L and Zhang W: Expression profiling of 83 matched pairs of lung adenocarcinomas and non-malignant adjacent tissue. https://www.ncbi.nlm.nih. gov/geo/query/acc.cgi?acc=GSE75037. 2016. Retrieve date: March 17, 2018.

34. Amin MB, Edge S, Greene F, Byrd DR, Brookland RK, Washington MK, Gershenwald JE, Compton CC, Hess KR, Sullivan DC, et al: AJCC Cancer Staging manual 8th. https://cancerstaging.org/references-tools/deskreferences/Pages/ default.aspx). 2016. Retrieve date: January 26, 2018.

35. Michaelsen SR, Aslan D, Urup T, Poulsen HS, Grønbæk K, Broholm H and Kristensen LS: DNA methylation levels of the $E L M O$ gene promoter $\mathrm{CpG}$ islands in human glioblastomas. Int J Mol Sci 19: E679, 2018.

36. Gardiner-Garden $\mathrm{M}$ and Frommer $\mathrm{M}$ : $\mathrm{CpG}$ islands in vertebrate genomes. J Mol Biol 196: 261-282, 1987.

37. Castaneda M, Chen L, Pradhan L, Li S, Zein R, Lee Y, Lim HS, Nam HJ and Lee J: A forkhead box protein C2 inhibitor: Targeting epithelial-mesenchymal transition and cancer metastasis. Chembiochem 19: 1359-1364, 2018.

38. Zhou X, Liu J, Zhang J, Wei Y and Li H: Flubendazole inhibits glioma proliferation by $\mathrm{G} 2 / \mathrm{M}$ cell cycle arrest and pro-apoptosis. Cell Death Disco 4: 18, 2018

39. Zhao M, Luo R, Liu Y, Gao L, Fu Z, Fu Q, Luo X, Chen Y, Deng X, Liang Z, et al: miR-3188 regulates nasopharyngeal carcinoma proliferation and chemosensitivity through a FOXO1-modulated positive feedback loop with mTOR-p-PI3K/AKT-c-JUN. Nat Commun 7: 11309, 2016.

40. Xue H, Hua LM, Guo M and Luo JM: SHIP1 is targeted by miR-155 in acute myeloid leukemia. Oncol Rep 32: 2253-2259, 2014.

41. Li J, Gong P, Lyu X, Yao K, Li X and Peng H: Aberrant CpG island methylation of PTEN is an early event in nasopharyngeal carcinoma and a potential diagnostic biomarker. Oncol Rep 31: 2206-2212, 2014

42. Yoshino Y, Yamazaki K, Ozaki Y, Sao T, Yoshida T, Mori T, Mori Y, Ochi S, Iga JI and Ueno SI: INPP5D mRNA expression and cognitive decline in Japanese Alzheimer's disease subjects. J Alzheimers Dis 58: 687-694, 2017.

43. McIntyre A and Ganti AK: Lung cancer-a global perspective. J Surg Oncol 115: 550-554, 2017.

44. Masuzawa K, Yasuda H, Hamamoto J, Nukaga S, Hirano T, Kawada I, Naoki K, Soejima K and Betsuyaku T: Characterization of the efficacies of osimertinib and nazartinib against cells expressing clinically relevant epidermal growth factor receptor mutations. Oncotarget 8: 105479-105491, 2017. 